\title{
Teaching, Research, and Management Self-Efficacy of Agricultural Universities' Teachers
}

\author{
Sidra Kiran \\ PirMehrAli Shah Arid Agriculture University, Rawalpindi. Pkistan \\ Erum Shahzadi, Asma Saher \\ National University of Modern Languages, Islamabad, Pakistan \\ Khuram Nabi \\ Holmes Institute, Sydney, Australia
}

\begin{abstract}
Teachers are the obligatory ingredients in enhancing the effective learning process at university through their keen potential for quality of teaching, research, and management. The faculty of agricultural universities in Pakistan is striving for productive agriculture education and research. Teachers possessing prevailing sense of self-efficacy are intrinsically motivated and additionally challenge themselves by multifarious tasks. The study was conducted to observe the self-efficacy levels of agricultural universities teachers at Faisalabad and Rawalpindi with respect to three particular domains named as teaching, research, and management. Stratified random sampling technique was used. From target population four strata, i.e., professors, associate professors, assistant professors, and lecturers were considered. As a result, 100 (59\%) teachers from University of Agriculture Faisalabad and 67 (40.1\%) teachers from PirMehr Ali Shah Arid Agriculture University Rawalpindi participated in the study as respondents. Data were collected through a questionnaire as an instrument of research. Pilot study was done on a sample of 24 teachers. Data were analyzed by using $t$-test and ANOVA test. High level of efficacy in terms of teaching, research, and management was found; teachers were fully confident in their beliefs to accomplish intended tasks. Teachers having less administrative tasks reported better performance in related tasks.
\end{abstract}

Keywords: self-efficacy, comparison, designations, agricultural universities

\section{Introduction}

Self-efficacy beliefs are said to be task-oriented not universal and general. High belief of self-efficacy to write a speech, but having low belief of self-efficacy to deliver the same speech is regarded as self-efficacy beliefs. Without seeing the situation, the impact of self-efficacy belief reading cannot be understood. The beliefs of self-efficacy are also particular to people possessing numerous roles. Though with respect to context specific nature of task, self-efficacy beliefs accomplish different courses of actions can covary (Bandura, 1997).

Sidra Kiran, Ph.D. Scholar, Department of Education Faculty of Social Sciences, PirMehrAli Shah Arid Agriculture University, Rawalpindi. Pkistan.

Erum Shahzadi, Master in English Literature, English Teacher, Department of English, National University of Modern Languages, Islamabad, Pakistan.

Asma Saher, Master in English Language \& Teaching, Department of English, National University of Modern Languages, Islamabad, Pakistan.

Khuram Nabi, Master in Businees Administration, Holmes Institute, Sydney, Australia. 
In addition to providing food to consumers and fibers to domestic industries, the agricultural sector is also a foundation of scarce foreign exchange earnings and it provides a market for industrial goods. In the meantime, Pakistan has the highest population growth rate in the Asia-Pacific region (2.4 percent annually or, in absolute numbers, an additional 3 to 4 million people each year). To fulfill the basic needs of the growing population, it is becoming essential attain food security for this fast-growing population by keeping in mind the growing rate of the population. To lessen the country's poverty at a considerable level, agricultural growth rates of at least 5 to 6 percent are obligatory. This agricultural production growth will need to take place through increasing yields and crop intensification as land and water resources are becoming increasingly scarce in Pakistan (Alam \& Naqvi, 2003).

The channel through which this can occur is the research in agriculture sector by utilizing the broad dissemination of new and improved technologies. For higher agricultural growth in developing countries, like Pakistan, investments in agriculture are therefore important in achieving intended targets.

\section{Objectives}

(1) To compare the variance between the level of designation and the teacher's perceived level of self-efficacy concerning teaching, research, and management.

(2) To describe the variance between and within groups and the teacher's perceived level of self-efficacy concerning teaching, research, and management.

\section{Literature Review}

With respect to land area and population, Pakistan is one of the largest countries in Asia. A large variability of agro-ecological zones ranging from coastal areas in the south to the Himalayan Mountains in the north is covered by the country; hence, it has great bulk for generating an extensive variety of food supplies. The agricultural sector is extremely dependent on water supply through either irrigation or water harvesting because most of Pakistan is categorized as arid or semi-arid. In 2003, 72 percent of Pakistan's agricultural area was irrigated. The largest network of irrigation canals in the world is in Pakistan, distributing water from the three major basins in Punjab Province. During the drought of 2000-2001, for example, the total production of wheat and rice declined by 10 and 19 percent, respectively. Wheat, sugarcane, cotton, and rice are the most significant crops produced in Pakistan. Combined, they accounted for more than three-quarters of total crop output in 2005. Wheat is the key staple food in Pakistan and it is by far the country's largest food crop in terms of production volume. In 2005, as compared to all of Africa and as much as all of South America Pakistan produced more wheat, an export crop that earns foreign exchange is cotton, but also a supplier of raw material to the local textile industry. In 2005, cotton production contributed 2 percent to Pakistan's GDP. Rice is not only an important food cash crop but also one of Pakistan's principal exports. Sugarcane is a major raw material for producing white sugar and gur (jaggery) (Government of the Republic of Zambia (GRZ), 2006).

As Pakistan is a country blessed by many natural resources, so by keeping in mind the above facts and figures, there is a great need of highly skilled man power to take maximum benefits from these natural resources especially in agriculture. Vital role can be played by highly self-efficacious teaching faculty at university level. Teachers possess tremendous power to make difference or positive change in the lives of their students.

Teachers success scenario in challenging situations is highly depend on their level of efficacy. The efficacy of teacher is relevant to their everyday well-being and the level of success depends on level of 
self-efficacy. Being teacher, the idea that it is possible to derive instructional efficacy with a high sense of self-efficacy is a very powerful tool. On the other hand, teachers possessing low self-efficacy believe that teachers can do little to help low-achieving students. Research examined that achievement of the students depends on the teachers' self-efficacy level. It is believed by highly self-efficacious teachers that they can reach slow learners by using appropriate methods and by encouraging more work. Under the umbrella of high self-efficacy, classroom problems can be solved through effective management techniques (Kiran, Yousuf, Siddique, \& Ehsan, 2014).

Self-efficacy is a powerful tool that will allow teachers to create instructional lessons and implement learning activities that will empower students. Through the self-efficacy of school personnel, children are educated and nurtured as a whole child and not just intellect. It is defined by the Self-Efficacy Theory that people can not only influence themselves but can also enhance human efficacy. It is believed that leaders should facilitate self-efficacy as it can be learned. The ingredients of self-efficacy fall into three categories of skills: focus, flow, and follow-through. Self-efficacy can be the facilitator to a detonation of empowerment and be the tool to create more than mere students, teachers, or leaders (Fleischhauer et al., 2000).

\section{Social Cognitive Theory}

How cognitive, behavioral, personal, and environmental factors interact to determine motivation and behavior is defined in the Social Cognitive Theory by Albert Bandura (Crothers, Hughes, \& Morine, 2008). According to Bandura, human functioning is the result of the interaction among all three of these factors (Crothers et al., 2008), as embodied in his Triadic Reciprocal Determinism Model (Wood \& Bandura, 1989). There are several factors that play a role in human behavior while it may seem that one factor is the majority, or lead reason. Additionally, the persuading factors are not of same strength, nor do they all happen simultaneously (Wood \& Bandura, 1989).

Self-efficacy beliefs believe that the intensity of goal completion can be motivated. "Self-efficacy refers to people's judgments about their capability to perform particular tasks. Self-efficacy related to task increases the effort and persistence regarding challenging tasks; therefore, increasing the likelihood that they will be completed" (Barling \& Beattie, 1983).

\section{Self-Efficacy Theory}

Self-efficacy beliefs are regarded as an important aspect of human motivation and behavior as they influence the actions that can affect one's life. Regarding self-efficacy, Bandura (1995) explained that it "refers to beliefs in one's capabilities to organize and execute the courses of action required to manage prospective situations". More simply, self-efficacy is what an individual believes he or she can accomplish using his or her skills under certain circumstances (Edwards, Rand, Lopez, \& Snyder, 2007).

Individuals are more likely to engage in activities for which they have high self-efficacy and less likely to engage in those they do not is the basic principle behind Self-Efficacy Theory.

\section{Materials and Methods}

\section{Population and Sample}

The population of the study comprised of teachers of agricultural universities in Faisalabad and Rawalpindi. According to the study, stratified random sampling technique was used. From target population four strata, i.e., professors, associate professors, assistant professors, and lecturers were considered. Fifty 
percent of the target population was selected randomly for each stratum. As a result, $100(59 \%)$ teachers from University of Agriculture Faisalabad and 67 (40.1\%) teachers from PirMehr Ali Shah Arid Agriculture University Rawalpindi participated in the study as respondents.

\section{Research Instrument}

A questionnaire used as tool of research was used on 5-point Likert scale. The tool used in the study to collect data after making some modifications under the light of the suggestions by five experts is taken from the study conducted by Maria Vera et al., in October, 2011. The 34 items in this scale were based on three domains, such as teaching, research, and management. There were 12 items under teaching domain, 10 items under research domain, and in management domain, there were 12 items. Pilot study was done on a sample of 24 teachers. In this regard, some more modifications were drawn. Judgmental validity is assured by a group of experts. 0.923 shows the reliability and validity of the tool used in the research to collect data.

\section{Data Collection}

Data were collected in an organized and structured manner from the both sampled Agricultural Universities at Faisalabad and Rawalpindi. Before collecting data, an institutional arrangement was established and request for participation in research was given in shape of letter to both the sampled universities to ensure the maximum participation of the teachers.

\section{Data Analysis}

Before analyzing the empirical data, the researcher briefly describes the personal characteristics of respondents. Some noteworthy characteristics of respondents are that there is high proportion of male teachers which were 89 from university of Agriculture Faisalabad 39 from arid Agriculture University Rawalpindi.

\section{Findings}

Table 1

Variance Between Designation and Perceived Teaching Efficacy

\begin{tabular}{llllll}
\hline \multirow{2}{*}{ Designation } & Mean difference & Std. error & \multirow{2}{*}{ Sig. } & \multicolumn{2}{c}{ 95\% confidence interval } \\
\cline { 5 - 6 } & & & & Lower bound & Upper bound \\
\hline Professor & 2.42519 & 1.68215 & 0.151 & -0.8964 & 5.7468 \\
Associate professor & -2.42519 & 1.68215 & 0.151 & -5.7468 & 0.8964 \\
Assistant professor & -3.49401 & 1.37861 & 0.012 & -6.2162 & -0.7718 \\
Lecturer & -2.03625 & 1.46352 & 0.166 & -4.9262 & 0.8537 \\
\hline
\end{tabular}

Table 1 shows the variance between levels of designation and the perceived level of teaching efficacy. The calculated $p$-value $(0.151)$ was greater than alpha value at 0.05 level of significance, which shows no significant difference between the perceived level of teaching efficacy and levels of designation of professors and associate professors. Furthermore, for assistant professors, the $p$-value $(0.012)$ is less than alpha value at 0.05 that shows significant difference between level of designation as assistant professor and the perceived level of teaching efficacy. In addition, for lecturers, the $p$-value which is 0.166 which is greater than alpha value 0.05 shows no significant difference between designations and the perceived level of teaching efficacy.

Therefore, it is found that there is no significant difference between the level of designation and the perceived level of teaching efficacy of the teachers of agricultural universities in Faisalabad and Rawalpindi except the respondents who are on the designation of assistant professor. 
Table 2

Variance Between Designation and Perceived Research Efficacy

\begin{tabular}{llllll}
\hline \multirow{2}{*}{ Designation } & Mean difference & Std. error & \multirow{2}{*}{ Sig. } & \multicolumn{2}{c}{$95 \%$ confidence interval } \\
\cline { 5 - 6 } & & & & Lower bound & Upper bound \\
\hline Professor & -1.45926 & 1.52724 & 0.341 & -4.4751 & 1.5566 \\
Associate professor & 1.45926 & 1.52724 & 0.341 & -1.5566 & 4.4751 \\
Assistant professor & -0.68192 & 1.25165 & 0.587 & -3.1536 & 1.7897 \\
Lecturer & 1.10709 & 1.33401 & 0.408 & -1.5272 & 3.7414 \\
\hline
\end{tabular}

Table 2 shows the variance between level of designation and the perceived level of research efficacy. For the designation of professors, the $p$-value which is 0.341 is greater than alpha value 0.05 shows no significant difference between the level of designation and the perceived level of research efficacy. For the designation of associate professors, the $p$-value $(0.341)$ is greater than alpha value 0.05 shows no significant difference between the level of designation and the perceived level of research efficacy. Furthermore, for assistant professors, the $p$-value which is 0.587 is greater than alpha value 0.05 shows no significant difference between designations and the perceived level of research efficacy. In addition, for lecturers, the $p$-value which is 0.408 is greater than alpha value 0.05 shows no significant difference.

Table 3

Variance Between Designation and Perceived Management Efficacy

\begin{tabular}{llllll}
\hline \multirow{2}{*}{ Designation } & Mean difference & \multirow{2}{*}{ Std. error } & \multirow{2}{*}{ Sig. } & \multicolumn{2}{c}{$95 \%$ confidence interval } \\
\cline { 5 - 6 } & & & & Lower bound & Upper bound \\
\hline Professor & 2.56889 & 2.14010 & 0.232 & -1.6570 & 6.7948 \\
Associate professor & -2.56889 & 2.14010 & 0.232 & -6.7948 & 1.6570 \\
Assistant professor & -4.09477 & 1.75392 & 0.021 & -7.5581 & -0.6314 \\
Lecturer & -0.46336 & 1.86195 & 0.804 & -4.1400 & 3.2133 \\
\hline
\end{tabular}

Table 3 shows the variance between level of designation and the perceived level of management efficacy. For the respondents on the designation of professors, the $p$-value which is 0.232 is greater than alpha value 0.05 shows no significant difference between the level of designation and the perceived level of management efficacy. Whereas for associate professor, the $p$-value 0.151 is greater than alpha value 0.232 that shows no significant difference between designations and the perceived level of management efficacy. Furthermore, for assistant professors, the $p$-value which is 0.012 is less than alpha value which is 0.05 that shows significant difference between the level of designation and the perceived level of management efficacy. In addition, the $p$-value for lecturers is 0.166 which is found to be greater than alpha value 0.05 shows no significant difference between the level of designation and the perceived level of management efficacy.

Table 4

Variance Between and Within Groups and the Perceived Level of Teaching Efficacy

\begin{tabular}{llllll}
\hline Domain & & ANOVA sum of squares & Mean square & F & Sig. (P) \\
\hline \multirow{3}{*}{ Teaching } & Between groups & 196.263 & 65.421 & & \\
& Within groups & 6033.701 & 37.017 & 1.767 & 0.155 \\
& Total & 6229.964 & & & \\
\hline
\end{tabular}

Note. $p$-value $>\alpha=0.155>0.05$. 
Table 4 shows variance between and within groups and the perceived level of teaching efficacy. The value of sum of squares between groups is 196.263, and for the same group, the value of mean square is 65.421 . Within groups, the value of sum of squares is 6033.701 and mean square value is 37.017 . The $p$-value $(0.155)$ is greater than tabulated value shows no significant result.

Table 5

Variance Between and Within Groups and the Perceived Level of Research Efficacy

\begin{tabular}{|c|c|c|c|c|c|}
\hline Domain & & Sum of squares & Mean square & $\mathrm{F}$ & Sig. (P) \\
\hline \multirow{3}{*}{ Research } & Between groups & 81.481 & 27.160 & \multirow{3}{*}{0.893} & \multirow{3}{*}{0.446} \\
\hline & Within groups & 4958.519 & 30.420 & & \\
\hline & Total & 5040.000 & & & \\
\hline
\end{tabular}

Note. $p$-value $>\alpha=0.446>0.05$.

Table 5 shows variance between and within groups and the perceived level of research efficacy. The value of sum of squares between groups is 81.481 and for the same group the value of mean square is 27.160. Within groups, the value of sum of squares is 4958.519 with mean square value 30.420 . The p-value (0.446) is greater than tabulated that value shows no significant difference.

Table 6

Variance Between and Within Groups and the Perceived Level of Management Efficacy

\begin{tabular}{|c|c|c|c|c|c|}
\hline \multirow[t]{2}{*}{ Domain } & & Sum of Squares & Mean Square & $\mathrm{F}$ & Sig. (P) \\
\hline & Between groups & 427.062 & 142.354 & & \\
\hline Management & $\begin{array}{l}\text { Within groups } \\
\text { Total }\end{array}$ & $\begin{array}{l}11649.561 \\
12076.623\end{array}$ & 71.470 & 1.992 & 0.117 \\
\hline
\end{tabular}

Note. $p$-value $>\alpha=0.117>0.05$.

Table 6 shows variance between and within groups and the perceived level of management efficacy. The value of sum of squares between groups is 427.062 , and for the same group, the value of mean square is 142.354. For within groups, the value of sum of squares is 11649.561 with mean square value 71.470 . The $p$-value $(0.117)$ is greater than tabulated value that shows no significant difference.

\section{Conclusions}

The following conclusions were drawn:

In the light of the findings, it is concluded that teachers of both the sampled universities have high level of efficacy in terms of teaching, research, and management and they are fully confident in own their beliefs to accomplish intended tasks successfully and they are much more able to provide opportunities for student communication by using a variety of models to meet the needs of the learners. Additionally, it seems that teachers who are having less administrative tasks report better performance in terms of teaching, research, and management tasks and are better able to polish their students in terms of research work, while assistant professors reported low efficacy regarding teaching and management due to a lot of administrative burden. Respondents reported a lot of administrative burden, lack of training, lack of resources needed for research activities, and lack of faculty as main reasons of low efficacy level.

\section{Recommendations}

In the light of findings, following recommendations were suggested: 
In order to make the teaching effective, the administrative burden of the teaching staff should be reduced by hiring assistant teachers.

The working staff involved in research projects assigned by the university must be provided with all the possible resources used in effective research.

At departmental level, meeting should be held in order to share vision and discussion on need based analysis between and among teaching staff.

Senior authorities should create research based activities among teachers to show their abilities.

\section{References}

Alam, S. M., \& Naqvi, M. H. (2003). Pakistan agriculture. Karachi, Pakistan: Pakistan Economist.

Bandura, A. (Ed.). (1995). Self-efficacy in changing societies. Cambridge: Cambridge University Press.

Bandura, A. (1997). Self-efficacy: The exercise of control. New York, NY, US: W H Freeman/Times Books/Henry Holt \& Co.

Barling, J., \& Beattie, R. (1983). Self-efficacy beliefs and sales performance. Journal of Organizational Behavior Management, $5(1), 41-51$.

Crothers, L. M., Hughes, T. L., \& Morine, K. A.(2008). Theory and cases in school-based consultation: A resource for school psychologists, school counselors, special educators and other mental health professionals. New York, NY, US: Routledge/Taylor \& Francis Group.

Edwards, L., Rand, K. L., Lopez, S. J., \& Snyder, C. R. (2007). Understanding hope: A review of measurement and construct validity research. In A. D. Ong \& M. van Dulmen (Eds.), Handbook of methods in positive psychology (pp. 83-95). New York: Oxford University Press.

Fleischhauer, G. S., Higgins, C. T., Losee, D. B., Nelson Jr, J. R., Ripley, R. L., Sano, M., ... \& Watkins, M. L. (2000). U.S. Patent No. 6,040,560. Washington, DC: U.S. Patent and Trademark Office.

Kiran, S., Yousuf, M. I., Siddique, B. N., \& Ehsan, T. (2014). Comparison of self-efficacy levels of the teachers of agricultural universities at Faisalabad and Rawalpindi. Academic Research International, 5(5), 291.

Wood, R., \& Bandura, A. (1989). Social cognitive theory of organizational management. Academy of Management Review, 14(3), 361-384.

Government of the Republic of Zambia (GRZ). (2006). Fifth National Development Plan, 2006-2010. Ministry of Finance and National Planning. 